\title{
How authentic leadership influences employee proactivity: the sequential mediating effects of psychological empowerment and core self-evaluations and the moderating role of employee political skill
}

Jing Zhang ${ }^{1,2}$, Lynda J. Song ${ }^{1,3^{*}}$, Yue Wang ${ }^{1}$ and Guangjian Liu ${ }^{1}$

\footnotetext{
* Correspondence: songjiwen@rbs. ruc.edu.cn

1 Department of Organization and Human Resources, School of Business, Renmin University of China, Beijing 100872, China ${ }^{3}$ Department of Organization and Human Resources, School of Business, Renmin University of China, Room 909, Mingde Business Building, No. 59 Zhongguancun Street, Haidian District, Beijing 100872, People's Republic of China Full list of author information is available at the end of the article
}

\begin{abstract}
This study aims to examine the relationship between authentic leadership and employee proactive behavior. Based on self-determination theory, we argue that such a relationship is sequentially mediated by psychological empowerment and core self-evaluations. In addition, political skill plays a moderating role in the third stage. These hypotheses are validated by a sample of 65 leaders and 275 subordinates from two private enterprises in mainland China. Results show that authentic leadership (Time 1) influences employees' proactive behavior (Time 3) through the psychological empowerment (Time 1) and core self-evaluations of employees (Time 2), and the relationship between core self-evaluations and proactive behavior is positively moderated by employees' political skill. In addition, bootstrapping results also verify the moderating role played by employees' political skill in the indirect relationship between authentic leadership and proactive behavior through core self-evaluations. Theoretical and managerial implications are further discussed in the light of these findings.
\end{abstract}

Keywords: Authentic leadership, Psychological empowerment, Core self-evaluations, Proactive behavior, Political skill

\section{Introduction}

Increasingly dynamic and competitive environments require employees to go beyond formal job duties and take proactive steps to contribute to their organizations (Griffin et al. 2007; Parker 1998). With the upsurge in self-managed teams as well as decentralization, employee proactive behavior is becoming more crucial to organizational success (Grant and Ashford 2008; Parker and Collins 2010). Given the considerable importance of employee initiatives, both scholars and practitioners are concerned about effective ways to elicit and promote employee proactivity (Parker and Collins 2010). Therefore, studies on the antecedents of proactive behavior are receiving more and more attention (Fuller et al. 2015; Shin and Kim 2015; Wu and Parker 2017).

(C) The Author(s). 2018 Open Access This article is distributed under the terms of the Creative Commons Attribution 4.0 International License (http://creativecommons.org/licenses/by/4.0/), which permits unrestricted use, distribution, and reproduction in any medium, provided you give appropriate credit to the original author(s) and the source, provide a link to the Creative Commons license, and indicate if changes were made. 
Leadership is considered to play a critical role in shaping motivation for employees' proactive behaviors (Morrison 2011; Parker et al. 2010; Parker et al. 2006). Although some scholars have examined the relationship between specific leader behaviors (e.g., empowering leadership, transformational leadership) and proactive behaviors (Den Hartog and Belschak 2012; Martin et al. 2013), empirical studies are still limited, especially for some emerging leadership styles, such as authentic leadership. Authentic leadership is defined as a pattern of leader behavior that draws upon and promotes both positive psychological capacities and a positive ethical climate, to foster greater self-awareness, internalized moral perspective, balanced information processing, and relational transparency (Walumbwa et al. 2008). Authentic leadership has become an important topic in leadership studies (Gardner et al. 2005), considering its potential for explaining leaders' impacts on human interactions in organizational settings (May et al. 2003). The core characteristic of authentic leaders is that they possess positive psychological states including confidence, optimism, hope and resilience and can also promote the development of these virtues in others (Gardner et al. 2005). After the emergence of authentic leadership, researchers have investigated its impact on employees' job outcomes, such as affective organizational commitment (Leroy et al. 2012) and voice (Hsiung 2012). In view of the fact that proactive behavior might change the status quo, which is not always welcomed by supervisors (Morrison and Phelps 1999; Parker et al. 2010; Parker and Collins 2010), employees might balance benefits and costs before engaging in these behaviors. Working in organizations with authentic leaders who are more likely to be temperate and open to change, employees may feel more comfortable engaging in proactive behavior. However, empirical studies directly linking authentic leadership with employees' proactive behavior are not sufficient. Previous studies have examined the influences of authentic leadership on voice, which is a form of employee proactive behavior (Morrison and Milliken 2000). However employee proactive behavior not only includes voice issues but is also about taking charge to improve working conditions (Morrison and Phelps 1999). In addition, Morrison and Milliken (2000) call for longitudinal tests to verify the causal linkage between authentic leadership and behaviors. The current research aims to fill in the gap with a longitudinal design.

In the current research, we propose a theoretical model that mainly draws on self-determination theory (SDT) (Deci and Ryan 2000). SDT asserts that individuals look forward to the satisfaction of three basic psychological needs (i.e., competence, relatedness and autonomy), and these basic psychological needs are held to be potent motivational forces that drive human attitudes, behavior, and well-being (Rosen et al. 2014). SDT reveals how employees' autonomous motivation affects their behaviors. In addition, working under the supervision of an authentic leader with high self-awareness and internalized moral perspective, employees are encouraged to share information and express their true thoughts and feelings. In this process, they perceive high levels of autonomy, and enhanced self-efficacy. In order to achieve their potential, they are likely to take proactive steps to go the extra mile on behalf of their organization.

Therefore, according to SDT, authentic leadership might affect proactive behavior by causing some changes in employees' psychological outcomes (Rosen et al. 2014). However, research pertaining to the psychological mechanism through which authentic 
leadership influences employee proactive behavior is scarce. What is the psychological mechanism through which this relationship is established? As SDT proposes, different types of autonomous motivation including intrinsic, integrated, and identified motivations provide reasons to pursue change to achieve a different future. Working under the supervision of an authentic leader characterized by relational transparency, selfawareness and balanced processing, employees' basic needs (e.g., autonomy) are more likely to be met through the enhancement of their psychological or cognitive conditions (e.g., the enhancement of their psychological empowerment). Employees with a high level of psychological empowerment are likely to experience more competence, selfdetermination and personal impact on their environment, which will increase their autonomous motivation to drive proactive goal processes (Parker and Collins 2010). According to SDT, the satisfaction of one's needs, such as the promotion of their psychological empowerment, can be transferred into intrinsic motivation and drive consequent behaviors. However, before conducting specific behaviors (e.g., proactive behavior), employees tend to make a fundamental and thorough assessment about their emotional resources and personal competence, as well as the degree to which they can control these behaviors. In other words, their overall self-evaluation may serve as an important bridge linking meeting needs and subsequent behaviors. Employees who are psychologically empowered will feel competence and self-determination, as well as a higher level of self-efficacy and self-control, which are very important factors for employees' core self-evaluations (Judge et al. 2005). Therefore, we infer that psychological empowerment and core self-evaluations can be used as mediating variables linking authentic leadership and employees' proactive behaviors. Furthermore, we explore what the boundary condition of the mechanism of influence is. Because employees with high levels of political skill can understand others effectively, and they are more likely to behave in appropriate ways in a given context (Ferris et al. 2005), the question then becomes whether relationship intensity differs among employees with different levels of political skill. This study tries to address these issues.

Our study makes several theoretical contributions: first, we contribute to the literature on authentic leadership. We are the first to propose and test the positive relationship between authentic leadership and employee proactive behavior. Compared to previous findings regarding authentic leadership and voice, our research deepens the understanding of the effect of authentic leadership on employee behavior. Second, drawing on SDT, we locate the sequential mediating effect of psychological empowerment and core self-evaluations in the relationship between authentic leadership and employee proactive behavior, which can help people to get a better understanding of its internal mechanisms. Third, employees' political skill is demonstrated in this research to serve as an important boundary condition influencing the indirect linkage between authentic leadership and employee proactive behaviors through core selfevaluations. Although authentic leadership can produce many positive results, the results might be different for different employees. Fourth, our findings also enrich the research results of proactive behavior and provide more antecedent explanations for proactive behavior. Our findings also have practical implications for business management, such as promoting employee proactive behavior, understanding the value of authentic leadership behavior, and the importance of developing employees' political skill. 
Our model is presented as follows (Fig. 1):

\section{Theory and hypothesis}

\section{Authentic leadership and proactive behavior}

Griffin et al. (2007) define proactive behavior as "the extent to which individuals engage in self-starting, future oriented behavior to change their individual work situations, their individual work roles, or themselves". It includes two dimensions: proactive idea implementation and proactive problem solving (Parker et al. 2006). Based on SDT and previous research results, we hypothesize that authentic leadership promotes proactive behavior.

SDT (Deci and Ryan 2000) asserts that individuals who are satisfied with three basic psychological needs (i.e., competence, relatedness and autonomy) might develop intrinsic motivation to drive behavior. These needs require that people pursue self-endorsed values and goals (Ryan and Deci 2008), which is aligned with behaviors reflective of authentic leadership. Leaders' authentic behavior will increase the autonomy of themselves because of higher self-awareness and self-regulation (Gardner et al. 2005). Leaders' authenticity will set a model that influences subordinates. In light of this statement, we infer that the four dimensions of authentic leadership can elicit employees' motivation to behave proactively. Our reasoning is as follows:

Firstly, authentic leaders can enhance followers' feelings of relatedness through relational transparency, and openly expressing their true thoughts and feelings. These actions are helpful to promote interpersonal understanding, and to lay a solid foundation for a better relationship between leaders and followers. Secondly, authentic leaders with high self-awareness and internalized moral identities can have a good idea of their impact on followers. They have a clear understanding of how to stimulate employees' internal motivation. For example, their willingness to share information (e.g., effective working methods and new skills) in the workplace can increase employees' sense of competence. Thirdly, authentic leaders' balanced processing can satisfy employees' needs for autonomy and competence in many ways. For one thing, leaders prefer to encourage employees' independent thinking and voicing behavior before leaders come to a decision (Gardner et al. 2005), which is conducive to cultivating followers' sense of competence and autonomy. For another, authentic leadership tends to pay more attention to

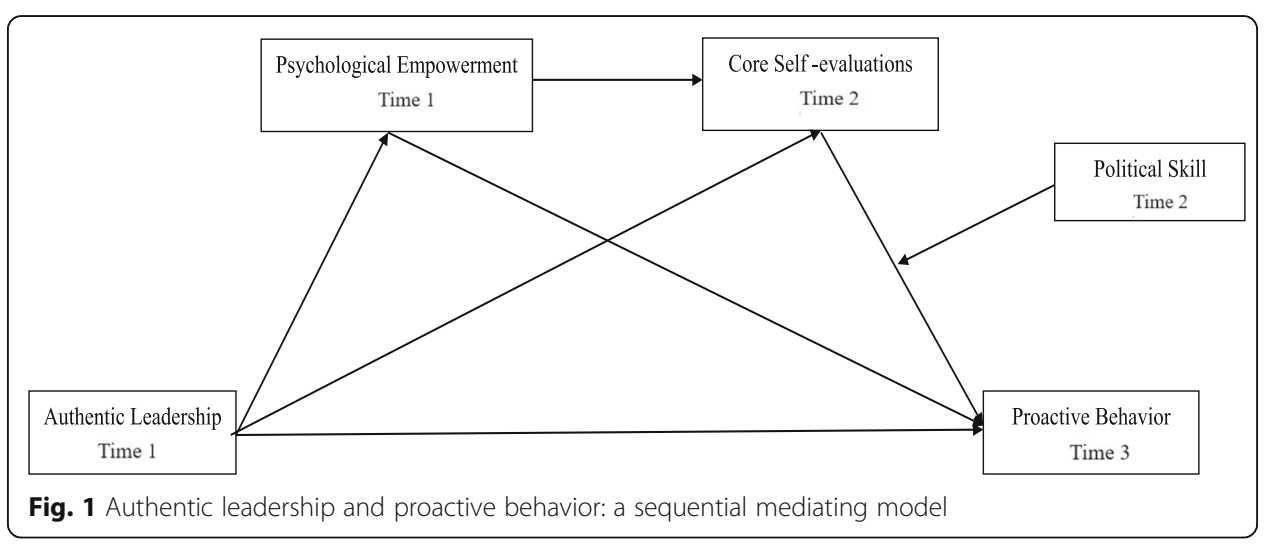


building a climate of trust and promotes interpersonal assistance among employees, which may improve employees' self-efficacy and satisfy their needs for competence.

In conclusion, through their own words and deeds, authentic leadership can meet the three basic needs of subordinates and their intrinsic motivation for proactively improving their work and situations. According to the above argument, we propose the following hypothesis:

Hypothesis 1: Authentic leadership is positively related to employees' proactive behavior.

\section{The mediating role of core self-evaluations}

According to SDT, the need for competence and autonomy contribute to intrinsic motivation (Greguras and Diefendorff 2009). As discussed above, authentic leadership can promote employee proactive behavior by fulfilling his/her three basic needs. Therefore, it will be of great value to clarify this relationship so as to understand why authentic leadership can promote employees' proactive behavior. In this section, we propose that core selfevaluations can serve as a bridge to link these two constructs. Core self-evaluations is defined as "fundamental assessments that people make about their worthiness, competence, and capabilities" (Judge et al. 2005), which include four self-evaluative components: selfesteem, generalized self-efficacy, emotional stability, and locus of control (Judge et al. 2003). Although core self-evaluations has previously been regarded as relatively stable, in recent years, scholars have proposed that core self-evaluations can be malleable (Bowling et al. 2010; Chang et al. 2012; Nübold et al. 2013). For example, Orth et al. (2010) empirically found people's self-esteem, which is one important element of core self-evaluations, can change over time. Some studies have found mean-level changes in neuroticism over time (Roberts et al. 2006).

SDT asserts that the satisfaction of employees' three basic needs can stimulate their intrinsic motivation to engage in proactive behaviors (Deci and Ryan 2000). Integrating SDT and the above statements, it is reasonable to argue that the increase of one's core self-evaluations can be treated as one important indicator of meeting these three basic needs to some extent. In this paper, we propose that authentic leadership can promote employees' core self-evaluations, and in turn yield more proactive behaviors for following reasons:

Firstly, one important feature of authentic leadership is balanced processing. With this character, leaders are likely to allow employees to participate in decision-making, which can increase employees' self-esteem and self-efficacy (Clapp-Smith et al. 2009; Laschinger et al. 2015). In addition, participative decision-making implies the opportunity an individual has in exercising control over matters that relate to his/her work and work outcomes (Liu et al. 2012). Thus, authentic leadership can enhance employees' sense of control. Secondly, research has shown that authentic leadership can increase employees' psychological capital (i.e., self-efficacy, optimism, hope and resilience) (Rego et al. 2012, 2016) and can also increase their positive emotions (Hsiung 2012; Zhou et al. 2014). According to the conservation of resources theory, adequate psychological resources are essential for people to control their emotions; thus, it is reasonable to argue that authentic leadership can increase people's emotional stability. Therefore, when employees perceive authentic leadership, they will increase their selfesteem and self-efficacy, and acquire emotional stability and self-control, so as to improve their core self-evaluations. 
With regards to the relationship between core self-evaluations and proactive behavior, we argue that core self-evaluations can predict employee proactive behavior in many ways. For one, core self-evaluations describe employees' level of positive self-regard. High levels of core self-evaluations may alleviate individuals' concerns about potential risks and obstacles involving proactive behaviors (Judge et al. 1997, 1998), because they have confidence in their knowledge, skills, and abilities to anticipate, plan and control their environment (e.g., Judge et al. 2005), and will exhibit more persistence (Wanberg et al. 2005). For another, people with high level core self-evaluations tend to engage in greater social network-building activity during socialization (Johnson et al. 2010). These strong social networks may help them succeed in proactive behaviors.

To sum up, we expect that employees with high core self-evaluations are more likely to engage in proactive behavior, thus strengthening the relationship between authentic leadership and proactive behavior. Taken together, we hypothesize the following:

Hypothesis 2: Employees' core self-evaluations mediate the relationship between authentic leadership and employees' proactive behavior.

\section{The mediating role of psychological empowerment}

Psychological empowerment is defined as a psychological state that employees must experience for managerial empowerment interventions to be successful, which comprises four main dimensions: meaning, competence, self-determination, and impact (Meyerson and Kline 2008; Spreitzer 1995). Previous studies have demonstrated the positive relationship between authentic leadership and employee psychological empowerment (Shapiralishchinsky and Tsemach 2014; Valsania et al. 2016; Zaabi et al. 2016; Zhu 2008).

Drawing from SDT, the three basic psychological needs-autonomy, competence, and relatedness-are crucial for human functioning (Deci and Ryan 2000; Ryan and Deci 2008). Some empirical studies have shown that psychological empowerment is linked with a wide range of positive organizational behaviors and outcomes, such as job satisfaction, job commitment, creative performance, customer satisfaction and work engagement (Jaiswal and Dhar 2016; Mathieu et al. 2006; Ugwu et al. 2014; Wang and Liu 2015; Wei et al. 2010).

In this paper, we suggest that psychological empowerment can improve employees' core self-evaluations. Employees with high levels of psychological empowerment will have more autonomy and can exert more impact on their work, which can boost their selfesteem and self-efficacy. In addition, feelings of competence, self-determination, and impact involved in psychological empowerment can make employees experience a sense of control over their tasks and environment, which may, to some extent, contribute to the shift of their locus of control from external to internal. On the basis of the foregoing statement, we formulate the following hypothesis:

Hypothesis 3: Psychological empowerment mediates the relationship between authentic leadership and core self-evaluations.

In addition, we propose that psychological empowerment can predict employee proactive behavior. SDT suggests that individuals whose basic psychological needs (competence, relatedness and autonomy) are satisfied in the organization will exhibit contextually required behaviors. Researchers show that employees with autonomy (like selfdetermination) are more likely to engage in proactive behaviors, including problemsolving and idea implementation (Parker et al. 2006; Zhang 2010). In fact, previous 
research, such as the effects of psychological empowerment on feedback-seeking behavior and role expansion, has provided some evidence supporting this view (Axtell and Parker 2003; Parker et al. 1997).

Based on the above statements, we predict that authentic leadership will promote proactive behavior via psychological empowerment:

Hypothesis 4: Employees' psychological empowerment mediates the relationship between authentic leadership and employees' proactive behavior.

\section{Sequential mediating effects of psychological empowerment and core self-evaluations}

As noted above, authentic leadership, psychological empowerment, and core selfevaluations are all antecedents of proactive behavior. In Hypothesis 2 and Hypothesis 4, we examine the independent mediation between authentic leadership and proactive behavior respectively. In Hypotheses 3, we infer authentic leadership has a positive influence on core self-evaluations through psychological empowerment. Furthermore, we suggest psychological empowerment and core self-evaluations might exert a sequential mediating effect between authentic leadership and proactive behavior. That is, authentic leadership can increase employee psychological empowerment, in turn improve his/her core selfevaluations, and finally increase employee willingness to perform more proactively.

In conclusion, we propose the following hypothesis:

Hypothesis 5: Employees' psychological empowerment and core self-evaluations sequentially mediate the relationship between authentic leadership and employees' proactive behavior.

\section{The moderating role of political skill}

Political skill is defined as "the ability to effectively understand others at work and to use such knowledge to influence others to act in ways that enhance one's personal and/or organizational objectives" (Ferris et al. 2005, p. 127). Political skill includes four dimensions: apparent sincerity, social astuteness, interpersonal influence, and networking ability (Ferris et al. 2005, 2007). Previous multiple studies have shown political skill is related to job performance (Bing et al. 2011; Ferris et al. 2005; Shi et al. 2011). With the ability of effectively understanding others, these individuals are more likely to behave in appropriate ways in the given context (Ferris et al. 2005). Clearly, individuals with more political skill will be better satisfied with their need for competence and relatedness needs, and achieve some valued outcomes (La Guardia et al. 2000) and feel connected to and understood by others (Baumeister and Leary 1995; Yang et al. 2015). Therefore, according to SDT, it is reasonable to introduce political skill as a boundary condition of proactive behavior.

We propose that political skill will moderate the positive relationship between core selfevaluations and proactive behavior. Although people with high levels of core selfevaluations have intrinsic motivations to perform well at work (Chiang et al. 2014), the final outcome may not be as they wish because interpersonal interaction might also play an important role in the workplace. Therefore, we argue that the strength of the relationship between core self-evaluations and employee proactive behavior depends on their political skill in the organization. First, political skill is especially important for proactive employees. Those who are proactive are usually predisposed to challenge the status quo, and often deviate from norms and supervisor expectations (Grant and Ashford 2008; 
Grant et al. 2011), which may threaten the position of leaders or damage the interests of other employees. In this case, we argue that political skill can help focal employees to effectively cope with pressure from their leader and colleagues, because employees who are politically skilled excel in interpersonal interaction and thrive in social situations (Breland et al. 2007). Second, in today's interdependent environment, it is hard for an individual to do a good job without the necessary assistance from others. Political skill can enable individuals to effectively understand social cues (Ferris et al. 2005), and construct extensive social networks (Breland et al. 2007). Thus it is reasonable to conclude that high political skill will strengthen the relationship between employees' core self-evaluations and their proactive behavior. Based on the above statement, we propose the following hypothesis:

Hypothesis 6: Political skill moderates the positive relationship between core selfevaluations and proactive behavior in such a way that the relationship is stronger when political skill is high rather than when it is low.

In addition, we argue that political skill will also moderate the indirect relationship between authentic leadership and proactive behavior. On the one hand, politically skilled individuals have the ability to understand situational demands at work, and are more likely to accurately perceive their authentic leaders' expectations. Thus, they will perform more proactively to live up to their leader's expectations. On the other hand, politically skilled individuals are more sensitive to others' requirements. Because of their influential, appropriate behaviors and genuineness, they are more likely to be relevant in others' eyes and may develop more trust and confidence in themselves (Ferris et al. 2007). According to Hypothesis 1, we propose that authentic leadership will inspire employees' proactive behavior because authentic behavior can satisfy employees' three basic needs. Obviously, employees with high levels of political skill have the ability to build a better relationship with leaders because they are able to effectively understand others at work and influence others to realize one personal and/or organizational objectives (Ferris et al. 2005). Therefore, it is possible that when political skill is high, authentic leadership will have a stronger influence on proactive behavior.

By integrating the logic associated with Hypotheses 2 and 6, we propose a mediated moderation framework: core self-evaluations are posited to mediate the relationships between authentic leadership and proactive behavior, and political skill moderates the core self-evaluations-proactive behavior linkage. We predict that the mediated relationships captured by Hypothesis 2 will be stronger when political skill is high. Thus, we propose a third-stage, indirect moderating effect of political skill in the relationship between authentic leadership and proactive behavior as follows:

Hypothesis 7: Political skill moderates the indirect relationships between authentic leadership and proactive behavior through core self-evaluations, such that the indirect effects of authentic leadership will be stronger under conditions of high political skill.

\section{Methods}

\section{Sample and procedures}

Our samples are comprised of full-time employees who are working in two manufacturing companies in China (one is a household electrical appliance enterprise in Beijing and the other is a petrochemical equipment company in Luoyang city). To minimize common method variance, we employed a time-lagged design in gathering our data 
wherein we administered surveys at three time points. The questionnaires were coded to match the surveys of supervisors and employees. In the first survey (Time 1), team members were asked to evaluate authentic leadership of their team supervisor and their own perception of psychological empowerment. Demographic data were also collected in this survey. About a month later (Time 2), team members filled out the second survey on core self-evaluations and political skill. At Time 3, which took place 1 month after Time 2, team supervisors assessed their subordinates' proactive behavior.

Our investigators distributed the questionnaires with envelopes to participants. All participants were assured of the confidentiality of their responses. After completion of the questionnaires, the participants returned them directly to our investigators in an enclosed envelope.

At Time 1, we distributed 66 questionnaires to leaders and 320 questionnaires to employees and received 65 useful responses from leaders and 314 from employees (response rate 98.48 and 98.12\%, respectively). At Time 2, we distributed 65 and 303 questionnaires to leaders and employees, while receiving 65 valid response from leaders and 291 from employees (response rate 100 and 96.03\%, respectively). At Time 3, we distributed 65 questionnaires to leaders and 287 to employees, and received 65 valid response from leaders and 284 from employees (response rate 100 and 98.95\%, respectively). As a result of administering the three surveys, we obtained a paired dataset composed of 64 team supervisors $(97.0 \%$ response rate) and 275 team members (85.9\% response rate). In the final sample, 54.9\% were men; the average age of employees was about 35.33 years (s.d. $=7.40 ; 32.3 \%$ were between 20 and 30 years old, 42.7\% between 31 and 40, 21.9\% between 41 and 50, and 3.2\% were older than 51); the average working time in the organization was about 6.09 years while the average working time with their team supervisor was about 4.27 years; subordinates interacted with their current supervisors "less than three times per week" (29.8\%), “3 6 times per week" (31.6\%), "7 10 times per week" (19.6\%), "11 15 times per week" (8.0\%), or "more than 15 times per week" (10.9\%).

\section{Measures}

To ensure the reliability and validity of the research instrument, we used a standard translation and back-translation procedure (Brislin 1980) to translate previously published English scales into Chinese. Unless otherwise noted, all the measures described here are six-point scales, ranging from 1 , "strongly disagree", to 6 , "strongly agree".

\section{Authentic leadership}

We adapted a 16-item scale developed by Neider and Schriesheim (2011) to measure authentic leadership. This scale contains four items for each of the four components of authentic leadership: self-awareness, relational transparency, moral perspective and balanced processing. Sample items include "She/he clearly knows his/her likes and dislikes (selfawareness)"; "She/he clearly states what she/he means (relational transparency)"; "She/he shows consistency between his/her beliefs and actions (moral perspective)" and "She/he asks for ideas that challenge his/her core beliefs (balanced processing)". Cronbach's alpha for the 16 -item total scale is 0.91 .

\section{Psychological empowerment}

We measure psychological empowerment with Spreitzer (1995)'s scale, which consists of 12 items used to assess the extent to which individuals experience four components 
of psychological empowerment: meaning, competence, self-determination, and impact. Sample items include "The work I do is very important to me (meaning)"; "I am confident about my ability to do my job (competence)"; "I have significant autonomy in determining how I do my job (self-determination)"; and "I have a great deal of control over what happens in my department (impact)". Cronbach's alpha for the 12-item total psychological empowerment scale is 0.78 .

\section{Core self-evaluations}

We use a 12-item scale from the Core Self-Evaluations Scale (Judge et al. 2003) to assess personal core self-evaluations. For example, one item is "I am confident I get the success I deserve in life". The Cronbach's alpha value for the 12 items is 0.82 .

\section{Proactive behavior}

To measure proactive behavior, we use the 8-item scale that Yang et al. (2016) revised to measure proactive behavior in China, with team leader evaluating their team subordinates. These items originally came from Griffin et al. (2007)'s work. A sample item is "Come up with ideas to improve the way in which your core tasks are done". Cronbach's alpha is 0.94 .

\section{Political skill}

We use an 18-item scale adapted from Ferris et al. (2005)'s to measure follower political skill. A sample item is "I spend a lot of time and effort at work networking with others". The Cronbach's alpha for the scale is 0.91 .

\section{Control variables}

We include several control variables in this study to address possible alternative explanations of authentic leadership and proactive behavior. Firstly, we collected data from two companies, so we use a categorical variable $(1=$ the household electrical appliance enterprise in Beijing; 2 = the petrochemical equipment company in Luoyang) to tap the difference between two companies (e.g. firm size etc.). As well, we use a dummy variable to identify whether employees in these teams are also leaders in another team (called as Leader-member), as a result of the nested organization. We also control for employee demographics, including gender $(0=$ male; $1=$ female), age (in years), working time with supervisors (in months), and working time in the organization (in months). Finally, the interaction frequency is controlled because it shows whether followers have a "closer" relationship with their leader (Antonakis and Atwater 2002), which may impact the relationship between authentic leadership and employees' proactive behavior.

\section{Descriptive statistics}

Table 1 displays the means, standard deviations, reliabilities and Pearson correlations for all the targeted variables in this study. As shown in Table 1, authentic leadership is positively related to psychological empowerment $(r=0.32, p<0.01)$, core selfevaluations $(r=0.18, p<0.01)$, and proactive behavior $(r=0.12, p<0.05)$. Psychological empowerment relates positively to core self-evaluations $(r=0.28, p<0.01)$, and proactive behavior $(r=0.12, p<0.05)$. Core self-evaluations are positively related to proactive behavior $(r=0.12, p<0.10)$ and follower political skill $(r=0.35, p<0.01)$, which provides initial evidence in support of our hypothesized relationships. Cronbach's alpha for all the scales is within acceptable limits $(>0.7)$. 
Table 1 Means, standard deviations, and correlations

\begin{tabular}{|c|c|c|c|c|c|c|c|c|c|c|c|c|c|c|}
\hline Variable & Mean & $S D$ & 1 & 2 & 3 & 4 & 5 & 6 & 7 & 8 & 9 & 10 & 11 & 12 \\
\hline 1. Leader-member & .21 & .41 & - & & & & & & & & & & & \\
\hline 2. Company & 1.47 & .50 & .06 & - & & & & & & & & & & \\
\hline 3. Follower age & 35.33 & 7.40 & $.26^{* *}$ & $.18^{* *}$ & - & & & & & & & & & \\
\hline $\begin{array}{l}\text { 4. Follower } \\
\text { gender }\end{array}$ & 1.45 & .50 & -.09 & $-.30^{* *}$ & .03 & - & & & & & & & & \\
\hline $\begin{array}{l}\text { 5. Working time } \\
\text { with supervisors }\end{array}$ & 51.24 & 44.41 & $.49^{* *}$ & .01 & $.31^{* *}$ & -.03 & - & & & & & & & \\
\hline $\begin{array}{l}\text { 6. Working time } \\
\text { in organization }\end{array}$ & 73.06 & 58.33 & $.50^{* *}$ & $.12^{*}$ & $.45^{* *}$ & -.00 & $.75^{* *}$ & - & & & & & & \\
\hline $\begin{array}{l}\text { 7. Interaction } \\
\text { frequency }\end{array}$ & 2.39 & 1.29 & .00 & -.02 & -.08 & -.05 & .00 & -.01 & - & & & & & \\
\hline $\begin{array}{l}\text { 8. Authentic } \\
\text { leadership ( } \mathrm{T} 1 \text { ) }\end{array}$ & 4.63 & .67 & .09 & $-.22^{* *}$ & -.07 & .05 & -.03 & -.09 & $.34^{* *}$ & $(.91)$ & & & & \\
\hline $\begin{array}{l}\text { 9. Psychological } \\
\text { empowerment (T1) }\end{array}$ & 4.61 & .60 & $.13^{*}$ & .00 & $.17^{* *}$ & .02 & .11 & .07 & $.17^{* *}$ & $.32^{* *}$ & (.78) & & & \\
\hline $\begin{array}{l}\text { 10. Core self- } \\
\text { evaluations (T2) }\end{array}$ & 4.14 & .55 & .11 & .04 & $.14^{*}$ & -.01 & .08 & .08 & $.20^{* *}$ & $.18^{* *}$ & $.28^{* *}$ & $(.82)$ & & \\
\hline $\begin{array}{l}\text { 11. Proactive } \\
\text { behavior (T3) }\end{array}$ & 4.03 & .80 & -.02 & $-.21^{* *}$ & -.01 & $.16^{*}$ & .09 & .11 & -.01 & $.12^{*}$ & $.12^{*}$ & $.12^{+}$ & $(.94)$ & \\
\hline $\begin{array}{l}\text { 12. Follower } \\
\text { political skill (T2) }\end{array}$ & 4.04 & 63 & .09 & .04 & .00 & $-.17^{* *}$ & .10 & .09 & .03 & $.24^{* *}$ & $.25^{* *}$ & $.35^{* *}$ & .01 & $(.91)$ \\
\hline
\end{tabular}

$N=275$. Cronbach's alphas are reported in the parentheses on the diagonal

${ }^{* *} p<.01 ;{ }^{*} p<.05 ;{ }^{+} p<.10$ (two-tailed)

\section{Results}

\section{Confirmatory factor analysis}

To examine the fit of the five-factor model, we performed a CFA by using AMOS 22 before testing the hypotheses. The five-factor model includes authentic leadership, psychological empowerment, core self-evaluations, proactive behavior and follower political skill. The proposed model demonstrates an acceptable fit $(\mathrm{X} 2 / d f=1.60$; NFI $=0.96 ; \mathrm{IFI}=0.98$; $\mathrm{TLI}=0.98 ; \mathrm{CFI}=0.98$; RMSEA $=0.05)$. In order to examine the discriminant validity, we compared the five-factor model with four alternative models (four-factor model, threefactor model, two-factor and single-factor model). The CFA results for the alternative models (Table 2) showed a poorer fit than the proposed five-factor model, which indicates that our variables are distinguishable.

\section{Tests of hypotheses}

We used hierarchical regression analyses in SPSS 23 to test the simple mediation models and the moderation model (Hypotheses 1 to 4, Hypotheses 6). To test the sequential mediation model (Hypotheses 5) and the moderated mediation model (Hypotheses 7), we adopted a bootstrapping analysis by using the PROCESS program in SPSS provided by Hayes (2013), which could test the conditional indirect effect to provide support for the sequential mediation and moderated mediation model.

Hypothesis 1 proposes that authentic leadership is positively related to proactive behavior. As shown in Table 3 (Model 2), after we took into account the control variables, we found that authentic leadership is marginal significantly and positively related to employees' proactive behavior $(\beta=0.12, p<0.10)$. Thus, Hypothesis 1 is basically supported. 
Table 2 Confirmatory factor analysis

\begin{tabular}{|c|c|c|c|c|c|c|}
\hline Model Factor & $\begin{array}{l}x / 1 \\
d f\end{array}$ & $\mathrm{NFI}$ & $\mathrm{IFI}$ & TLI & $\mathrm{CFI}$ & RMSEA \\
\hline Five-factor model & 1.60 & 0.96 & 0.98 & 0.98 & 0.98 & 0.05 \\
\hline $\begin{array}{l}\text { Four-factor model: authentic leadership and psychological } \\
\text { empowerment combined }\end{array}$ & 6.19 & 0.83 & 0.85 & 0.82 & 0.85 & 0.14 \\
\hline $\begin{array}{l}\text { Three-factor model: authentic leadership, psychological empowerment, } \\
\text { and core self-evaluations combined }\end{array}$ & 9.64 & 0.72 & 0.74 & 0.70 & 0.74 & 0.18 \\
\hline $\begin{array}{l}\text { Two-factor model: authentic leadership, psychological empowerment, } \\
\text { and core self-evaluations combined; proactive behavior and political skill } \\
\text { combined }\end{array}$ & 18.46 & 0.45 & 0.47 & 0.39 & 0.46 & 0.25 \\
\hline Single-factor model & 25.06 & 0.24 & 0.25 & 0.16 & 0.24 & 0.29 \\
\hline Decision value of each index & $<5$ & $>0.9$ & 0.9 & 0.9 & $>0.9$ & $<0.08$ \\
\hline
\end{tabular}

$N=275$

We applied Baron and Kenny (1986)'s strategy to test the mediating effect with multiple regressions. Hypothesis 2 proposes that core self-evaluations mediate the relationship between authentic leadership and proactive behavior. Results in Table 3 demonstrate that authentic leadership is significantly and positively related to core self-evaluations (Model $8, \beta=0.14, p<0.05)$. Authentic leadership is significantly and positively related to employee proactive behavior $(\mathrm{H} 1)$. When core self-evaluations are included in regression analyses, core self-evaluations are significantly and positively related to proactive behavior (Model 3, $\beta=0.12, p<0.10$ ), but the significant effect of authentic leadership and proactive behavior become insignificant (Model $3, \beta=0.10$, n.s). These results indicate that core self-evaluations fully mediate the relationship between authentic leadership and proactive behavior. Thus, Hypothesis 2 is supported.

Table 3 Regression results testing the mediating effect of psychological empowerment and core self-evaluations

\begin{tabular}{|c|c|c|c|c|c|c|c|c|c|}
\hline \multirow[t]{2}{*}{ Variable } & \multicolumn{4}{|c|}{ Proactive behavior } & \multicolumn{2}{|c|}{$\begin{array}{l}\text { Psychological } \\
\text { empowerment }\end{array}$} & \multicolumn{3}{|c|}{ Core self-evaluations } \\
\hline & $\mathrm{M}_{1}$ & $\mathrm{M}_{2}$ & $M_{3}$ & $\mathrm{M}_{4}$ & $\mathrm{M}_{5}$ & $M_{6}$ & $\mathrm{M}_{7}$ & $M_{8}$ & $M_{9}$ \\
\hline Leader-member & -0.08 & -0.10 & -0.11 & -0.11 & 0.10 & 0.05 & 0.08 & 0.05 & 0.04 \\
\hline Company & $-0.19^{* *}$ & $-0.17^{*}$ & $-0.17^{* *}$ & $-0.17^{* *}$ & 0.00 & 0.06 & 0.02 & 0.05 & 0.04 \\
\hline Follower age & -0.05 & -0.05 & -0.07 & -0.08 & $0.19^{* *}$ & $0.18^{* *}$ & $0.15^{*}$ & $0.14^{*}$ & 0.11 \\
\hline Follower gender & 0.10 & 0.09 & 0.09 & 0.09 & 0.04 & 0.03 & 0.00 & 0.00 & 0.00 \\
\hline Working time with supervisor & 0.00 & 0.00 & 0.00 & -0.01 & 0.10 & 0.11 & 0.04 & 0.04 & 0.02 \\
\hline Working time in organization & $0.20^{*}$ & $0.22^{*}$ & $0.22^{*}$ & $0.23^{*}$ & -0.14 & -0.10 & -0.05 & -0.04 & -0.01 \\
\hline Interaction frequency & -0.01 & -0.05 & -0.07 & -0.06 & $0.18^{* *}$ & 0.08 & $0.21^{* *}$ & $0.16^{*}$ & $0.15^{*}$ \\
\hline Authentic leadership & & $0.12^{+}$ & 0.10 & 0.09 & & $0.30^{* *}$ & & $0.14^{*}$ & 0.08 \\
\hline Psychological empowerment & & & & $0.11^{+}$ & & & & & $0.20^{* *}$ \\
\hline Core self-evaluations & & & $0.12^{*}$ & & & & & & \\
\hline$R^{2}$ & 0.08 & 0.09 & 0.11 & 0.08 & 0.08 & 0.15 & 0.07 & 0.09 & 0.12 \\
\hline F & $3.32^{* *}$ & $3.36^{* *}$ & 1.50 & $2.05^{*}$ & $3.16^{* *}$ & $23.22^{* *}$ & $2.90^{* *}$ & $3.17^{* *}$ & $4.07^{* *}$ \\
\hline$\Delta R^{2}$ & 0.08 & 0.01 & 0.01 & 0.02 & 0.08 & 0.07 & 0.07 & 0.02 & 0.03 \\
\hline$\Delta F$ & $3.32^{* *}$ & $3.43^{+}$ & $3.48^{* *}$ & $7.10^{* *}$ & 0.83 & $6.54^{*}$ & $2.90^{* *}$ & $4.78^{*}$ & $10.39^{* *}$ \\
\hline
\end{tabular}


Hypothesis 3 proposes that psychological empowerment mediates the relationship between authentic leadership and core self-evaluations. Results in Table 3 demonstrate that authentic leadership is significantly and positively related to psychological empowerment (Model $6, \beta=0.30, p<0.01$ ). Authentic leadership is significantly and positively related to core self-evaluations (Model $8, \beta=0.14, p<0.05$ ). When psychological empowerment is included in regression analysis, psychological empowerment is significantly and positively related to core self-evaluations (Model 9, $\beta=0.20, p<0.01$ ), but the significant effect of authentic leadership and core self-evaluations becomes insignificant (Model 9, $\beta=0.08, n . s$ ). These results indicate that psychological empowerment fully mediates the relationship between authentic leadership and core self-evaluations. Thus, Hypothesis 3 is supported.

Hypothesis 4 proposes that psychological empowerment mediates the relationship between authentic leadership and proactive behavior. Results in Table 3 demonstrate that authentic leadership is significantly and positively related to psychological empowerment (Model 6, $\beta=0.30, p<0.01$ ). Authentic leadership is significantly and positively related to proactive behavior $(\mathrm{H} 1)$. When psychological empowerment is included in regression analyses, psychological empowerment is marginally significantly and positively related to proactive behavior (Model 4, $\beta=0.11, p<0.10$ ), but the significant effect of authentic leadership and proactive behavior becomes insignificant (Model $4, \beta=0.09$, n.s). These results indicate that psychological empowerment fully mediates the relationship between authentic leadership and proactive behavior. Thus, Hypothesis 4 is supported.

In order to test the hypothesis of whether psychological empowerment and core selfevaluations sequentially mediate the impact of authentic leadership on employee proactive behavior, we performed a sequential mediation analyses (Model 6 as described in PROCESS, 10,000 ) with bootstrapping methods. As shown in Table 4, the total indirect effect of authentic leadership on employee proactive behavior is found to be significant $(\beta=0.0513$, $95 \% \mathrm{CI}=[0.0051,0.1188])$. While testing for sequential multiple mediation, the specific indirect effect of authentic leadership on employee proactive behavior through both psychological empowerment and core self-evaluations is found to be significant with a point estimate of 0.0076 and a $95 \%$ confidence interval between 0.0004 and 0.0251 , providing full support for Hypothesis 5 . Hence, this study shows that psychological empowerment and core self-evaluations sequentially mediate the relationship between authentic leadership and employee proactive behavior.

Hypothesis 6 predicts an interaction effect. According to Table 5 (Model 4), the interaction term between core self-evaluations and follower political skill is significant and

Table 4 Total effect, direct effect, indirect effect of authentic leadership on proactive behavior

\begin{tabular}{llllllll}
\hline & Path & Effect & SE/Boot SE & $t$ & $p$ & LLCl & ULCl \\
\hline Total effect & & 0.1428 & 0.0771 & 1.8514 & 0.0652 & -0.0091 & 0.2947 \\
Direct effect & & 0.0915 & 0.0800 & 1.1438 & 0.2538 & -0.0660 & 0.2491 \\
Indirect effect & Total & 0.0513 & 0.0281 & & & 0.0051 & 0.1188 \\
& $\mathrm{AL} \rightarrow \mathrm{PE} \rightarrow \mathrm{PB}$ & 0.0334 & 0.0250 & & & -0.0090 & 0.0922 \\
& $\mathrm{AL} \rightarrow \mathrm{CSE} \rightarrow \mathrm{PB}$ & 0.0102 & 0.0103 & & & -0.0030 & 0.0412 \\
& $\mathrm{AL} \rightarrow \mathrm{PE} \rightarrow \mathrm{CSE} \rightarrow \mathrm{PB}$ & 0.0076 & 0.0057 & & & 0.0004 & 0.0251 \\
\hline
\end{tabular}

Lower and higher conditions are 1 standard deviation above and below the mean. Bootstrapped $95 \%$ confidence intervals are derived from 10,000 replications. $S E$ standard error, $C l$ confidence interval, $A L$ authentic leadership, $P E$ psychological empowerment, CSE core self-evaluations, $P B$ proactive behavior 
positive $(\beta=0.15, p<0.05)$, indicating that follower political skill positively moderates the relation between core self-evaluations and proactive behavior. In order to further verify H6, we tested the significance of the simple slopes when core self-evaluations predicts employee proactive behavior at higher (1 SD above the mean) and lower (1 SD below the mean) levels of follower political skill, and plotted the moderation of follower political skill according to Aiken and West (1991). As shown in Fig. 2, the positive relationship between core self-evaluations and employee proactive behavior is stronger when follower political skill is high $(\beta=0.33, p<0.01)$ than when it is low $(\beta=0.12$, n.s). Taken together, Hypothesis 6 is supported.

$\mathrm{H} 7$ predicts that the indirect effect of authentic leadership on employee proactive behavior via core self-evaluations is moderated by follower political skill. Table 6 presents the indirect effect of authentic leadership on employee proactive behavior at higher (1 SD above the mean) and lower (1 SD below the mean) levels of follower political skill by using the PROCESS program (Model 14). As shown in Table 6, when follower political skill is high, authentic leadership has an indirect effect on proactive behavior via core self-evaluations $(\beta=0.0469,95 \% \mathrm{CI}=[0.0095,0.1149])$. When follower political skill is low, the indirect effect of authentic leadership on proactive behavior via core self-evaluations is not significant $(\beta=0.0035,95 \% \mathrm{CI}=[-0.0161,0.0349])$, where the 95\% bias-corrected confidence interval contains zero. Thus, Hypothesis 7 is supported.

\section{Discussion}

The main aim of this paper is to deepen our understanding of why and how authentic leadership exerts influence on employee proactive behavior. Analysis of data from 275 subordinate-supervisor dyads at two private companies in China shows that the seven hypotheses about the influence of authentic leadership on employee proactive behavior through the sequential mediating effects of psychological empowerment and core-self evaluations, and the moderating effect of political skill

Table 5 Regression results testing the moderating effect of follower political skill

\begin{tabular}{lllll}
\hline Variable & \multicolumn{3}{l}{ Proactive behavior } & \\
\cline { 2 - 4 } & $\mathrm{M}_{1}$ & $\mathrm{M}_{2}$ & $\mathrm{M}_{3}$ & $\mathrm{M}_{4}$ \\
\hline Leader-member & -0.08 & -0.09 & -0.09 & -0.10 \\
Company & $-0.19^{* *}$ & $-0.19^{* *}$ & $-0.19^{* *}$ & $-0.21^{* *}$ \\
Follower age & -0.05 & -0.07 & -0.07 & -0.08 \\
Follower gender & 0.10 & 0.10 & 0.09 & 0.08 \\
Working time with supervisor & 0.00 & -0.01 & -0.01 & -0.03 \\
Working time in organization & $0.20^{*}$ & $0.21^{*}$ & $0.21^{*}$ & $0.23^{*}$ \\
Interaction frequency & -0.01 & -0.04 & -0.04 & -0.05 \\
Core self-evaluations & & $0.14^{*}$ & $0.14^{*}$ & $0.16^{*}$ \\
Follower political skill & & -0.01 & 0.00 \\
$Z$ Core self-evaluations ${ }^{*}$ Follower political skill & & & $0.15^{*}$ \\
$R^{2}$ & 0.08 & 0.10 & 0.10 & 0.12 \\
$F$ & $3.32^{* *}$ & $3.58^{* *}$ & $3.17^{* *}$ & $3.51^{* *}$ \\
$\Delta R^{2}$ & 0.08 & 0.02 & 0.00 & 0.02 \\
$\Delta F$ & $3.32^{* *}$ & $5.04^{*}$ & 0.02 & $5.97^{*}$ \\
\hline Standardized coefficients are reported. ${ }^{*} p<0.05, * * 0<0.01$ (two -tailed) & &
\end{tabular}




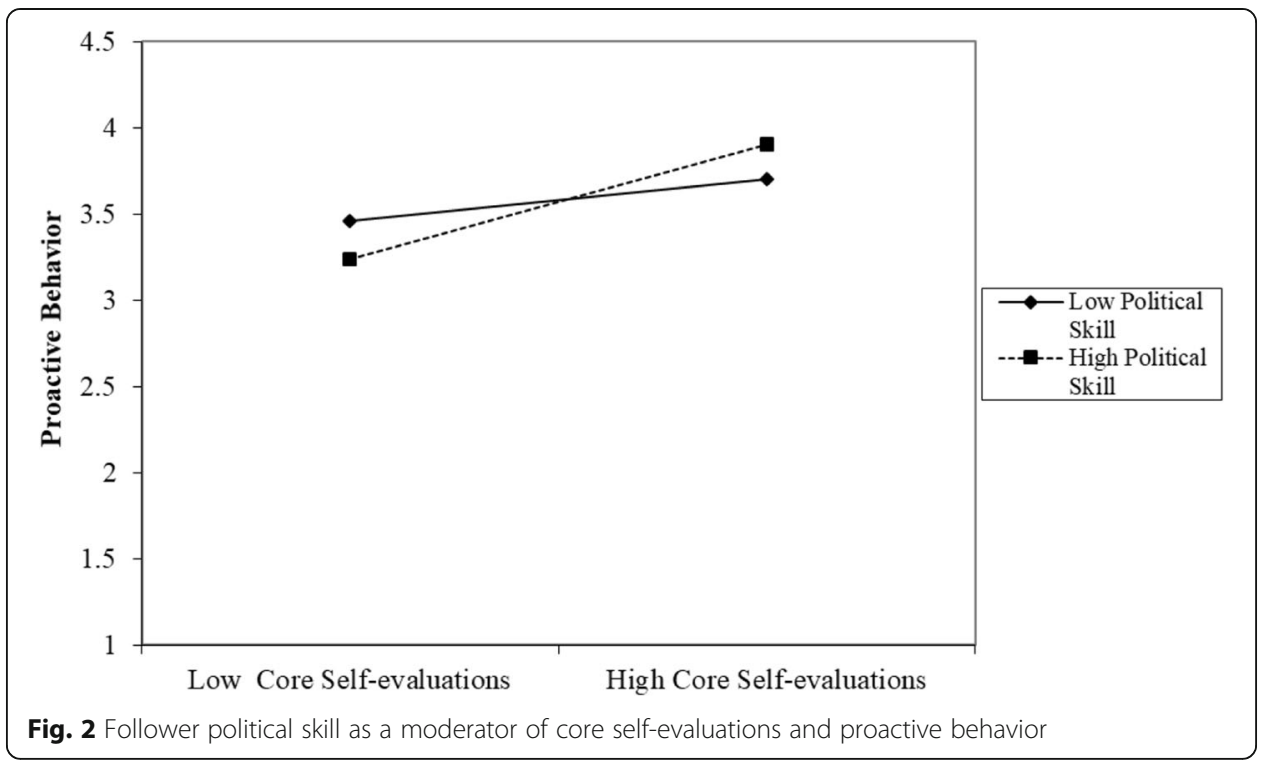

are verified. We first examine the direct effect of authentic leadership on proactive behavior (Hypotheses 1), and unfortunately, the result is only marginally significant. Nevertheless, some articles on statistical testing methods indicate that the existence of a mediating effect does not need the premise of a significant main effect (Mackinnon et al. 2000; Shrout and Bolger 2002). It is still meaningful to explore the mediation mechanism of the model when the main effect is not sufficiently significant (Preacher and Hayes 2004; Zhao et al. 2010). Therefore, our findings are acceptable. Then we examine the mediating role of psychological empowerment and core self-evaluations. The results indicate that psychological empowerment and core self-evaluations not only exert a mediating role, but also sequentially mediate the relationship between authentic leadership and employee proactive behavior. Furthermore, in order to gain a better understanding of the boundary conditions by which authentic leadership exerts its influence, we explore the moderating role of employee political skill and find that political skill positively moderates the relation between core selfevaluations and proactive behavior. That is, for those with high levels of political skill, the relationship is stronger. With these findings, this study attempts to add new value to current theoretical research and management practice. In the following sections, we further interpret the theoretical contribution and practical implications of this study.

\section{Theoretical implications}

Our study makes four significant theoretical contributions to extant research.

Table 6 Conditional indirect effect of authentic leadership on proactive behavior

\begin{tabular}{lllll}
\hline & Effect & Boot SE & LLCl & ULCl \\
\hline Low political skill & 0.0035 & 0.0121 & -0.0161 & 0.0349 \\
Mean political skill & 0.0252 & 0.0153 & 0.0036 & 0.0672 \\
High political skill & 0.0469 & 0.0255 & 0.0095 & 0.1149 \\
\hline
\end{tabular}

Lower and higher conditions are 1 standard deviation above and below the mean. Bootstrapped $95 \%$ confidence intervals are derived from 10,000 replications. SE standard error, $\mathrm{Cl}$ confidence interval 
First, we contribute to the literature on authentic leadership by proposing and verifying the positive relationship between authentic leadership and employee proactive behavior. Although previous studies have provided evidence of the positive linkage between authentic leadership and voice behavior, research on proactive behavior is lacking. Our study fills the gap of understanding the relationship between authentic leadership and the proactive behavior of employees.

Second, we develop the sequential mediating mechanism of the relationship. Drawing upon SDT, we contend that psychological empowerment and core self-evaluations can serve as useful lenses to the understanding of this relationship and verify this empirically. These two constructs not only work alone, but could also exert sequential mediating effects linking authentic leadership and employee proactive behavior. These findings are of great importance, as they provide insights into how leaders' authenticity could influence employees' psychological perceptions and core self-evaluations, which in turn affects their behavior.

Third, we verify that political skill serves as a moderator during the influence process of authentic leadership on proactive behavior. This finding is valuable because it explains how employee political skill is an important boundary condition between the relationship of authentic leadership and proactive behavior. More importantly, we explain this effect from the perspective of SDT. Thus, we integrate the authentic leadership, employee proactive behavior, and political skill literature within the framework of SDT, and aim to promote the development of SDT.

Fourth, we advance the literature on proactive behavior. The past several decades have seen a rapid increase in the interest in leaders' influence on their subordinates. Yet few empirical studies have explored the role played by authentic leadership in facilitating subordinate proactive behavior. In this research, we propose and empirically verify authentic leadership as an antecedent to subordinate proactive behavior. We also show that psychological empowerment and core self-evaluations can serve as a sequential mediating mechanism and that political skill can act as an important boundary condition during the process, which enriches the current research on proactive behavior.

\section{Practical implications}

Apart from theoretical contributions, our study has valuable practical implications as well.

First, this study shows the importance of authentic leadership, which is characterized by self-awareness, balanced processing, an internalized moral perspective and relational transparency. As demonstrated in the present research, authentic leadership can enhance employee psychological empowerment, core self-evaluations, and in turn increase their proactive behavior. Therefore, authentic features should be given considerable weight in the process of selecting managers. In addition, effective measures should be taken to implement training and development activities aimed at increasing authentic leadership. For example, leaders should learn how to openly share information with followers, to provide followers with an opportunity to participate in decision-making processes, and to motivate them to share their opinions.

Second, in light of the importance of political skill, managers should strive to seek employees who possess some level of this skill, as these kinds of individuals might find 
it easier to effectively adapt to any work environment. In fact, considerable importance has been attached to political skill. For example, although proactive behaviors are beneficial to the functioning of the organization, employees also face the risk of offending and threatening their supervisors. Therefore, for the sake of safety, employees with relatively low levels of political skill may hesitate to behave proactively.

Third, leaders should also bear it in mind that employees may respond differently to their authentic leadership behaviors. As shown in this study, for followers with high levels of political skill, leaders' authentic behaviors can elicit more proactive behavior. On the contrary, low levels of political skill may attenuate the positive effect of authentic leadership behaviors. From this point of view, leaders need to adopt different leadership styles directed at employees in accordance with their varied qualities.

\section{Limitations and future directions}

Several limitations in this study should be acknowledged. First, we only measure general proactive behavior. Indeed, there are various kinds of proactive behaviors, such as voice, taking charge and feedback-seeking behavior. Although these behaviors are proactive in nature, their points of focus may be different from each other; thus, the predicting power of authentic leadership on these different behaviors could be different. We suggest future research differentiates these behaviors and explores the predicting power of authentic leadership on each in detail.

Secondly, in order to verify the causality of variables used in our theoretical model, we collect superior-subordinate dyad data from three time points (Time 1, Time 2, and Time 3). Even so, we cannot fully ascertain the causal relationship of these variables, because two of these variables (i.e., authentic leadership and psychological empowerment) are measured at the same time (Time 1). Therefore, future studies can extend our study by collecting data at four time points or adopt a within-person design to capture change dynamics and causal relationships.

Third, previous studies find a certain degree of overlap between authentic leadership and other leadership behaviors, such as transformational leadership, ethical leadership and servant leadership (Hoch et al. 2016). Thus, whether authentic leadership could exert influence on employee proactive behavior beyond and above other leadership styles is uncertain. We suggest future research to further investigate the relationships proposed in this study after controlling for other related but different leadership styles.

Fourth, our data is collected from two large companies. Given the differences between different industries and areas, the external validity of the present research might be not that strong, and we suggest future scholars to examine our hypothesis with more data. In addition, because the main effect of authentic leadership and proactive behavior is marginally significant, we speculate it might be due to the limited sample size of our current research which is not enough to verify the significant effect of the relationship between authentic leadership and proactive behavior. Future studies can increase the sample size and test the main effect.

Fifth, we adopt a self-determination perspective to illustrate our model, but have not been able to test the three basic psychological needs. In the future, researchers might add basic psychological needs variables for comparative studies. 
Last but not least, from the perspective of SDT, this study finds that psychological empowerment and core self-evaluations play a sequential mediating role in the relationship between authentic leadership and proactive behavior. However, leaders might influence their subordinates in many ways. Therefore, future researchers could further investigate the relationship through other lenses, such as leader-member exchange, social learning and emotional contagion theories.

\title{
Conclusion
}

Given the critical role of proactive behavior in organizations, effective measures should be taken to inspire employee proactivity. Based on SDT, this research excavates the psychological mechanism through which authentic leadership is positively related to employee proactive behavior, and we find that psychological empowerment and core self-evaluations play a mediating role respectively and sequentially. Empirical evidence also indicates the moderating effect of employee political skill in the relationship between core self-evaluations and proactive behavior. Despite the limitations of this paper, we offer some valuable contributions to the discussion on authentic leadership and proactive behavior. We encourage future research to pay more attention to the positive influence of authentic leadership together with its internal mechanisms and boundary conditions.

\section{Acknowledgements}

This research is supported by a grant from the Chinese National Natural Science Foundation (project code: 71372161; 71772176), and supported by the Outstanding Innovative Talents Cultivation Funded Programs 2016 of Renmin University of China. The authors here with express their appreciation for its support. The authors thank the valuable comments and suggestions from the anonymous reviewers, and acknowledge the editorial assistance in revising this paper.

\section{Funding}

This research is supported by a grant from the Chinese National Natural Science Foundation (project code: 71372161; 71772176), and supported by the Outstanding Innovative Talents Cultivation Funded Programs 2016 of Renmin University of China.

Availability of data and materials

Not applicable.

\section{Authors' contributions}

We declare that all authors have equal contribution in this paper. All authors read and approved the final manuscript.

\author{
Authors' information \\ Jing Zhang is a Ph.D. student in the School of Business at Renmin University of China. Her research interests cover \\ organizational behavior and human resource management \\ Lynda J. Song is an associate professor of management in the Department of Organization and Human Resource \\ Management, Business School, Renmin University of China. Her research interests include organizational control \\ mechanisms, emotional intelligence, and cross cultural studies. \\ Yue Wang is a master student in the School of Business at Renmin University of China. Her research interests cover \\ organizational behavior and human resource management. \\ Guangjian Liu is a Ph.D student in the School of Business at Renmin University of China. Her research interests cover \\ organizational behavior and human resource management.
}

Competing interests

The authors declare that they have no competing interests.

\section{Publisher's Note}

Springer Nature remains neutral with regard to jurisdictional claims in published maps and institutional affiliations.

\section{Author details}

1 Department of Organization and Human Resources, School of Business, Renmin University of China, Beijing 100872, China. 'Department of Organization and Human Resources, School of Business, Renmin University of China, Room 104, No. 3 building of Yiyuan, No. 59 Zhongguancun Street, Haidian District, Beijing 100872, People's Republic of China. ${ }^{3}$ Department of Organization and Human Resources, School of Business, Renmin University of China, Room 909, Mingde Business Building, No. 59 Zhongguancun Street, Haidian District, Beijing 100872, People's Republic of China. 
Received: 28 September 2017 Accepted: 1 February 2018

Published online: 27 February 2018

\section{References}

Aiken, L. S., \& West, S. G. (1991). Multiple regression: Testing and interpreting interactions - Institute for Social and Economic Research (ISER). Evaluation Practice, 14(2), 167-168.

Antonakis, J., \& Atwater, L. (2002). Leader distance: A review and a proposed theory. Leadership Quarterly, 13(6), 673-704

Axtell, C. M., \& Parker, S. K. (2003). Promoting role breadth self-efficacy through involvement, work redesign and training. Human Relations, 56(1), 113-131.

Baron, R. M., \& Kenny, D. A. (1986). The moderator-mediator variable distinction in social psychological research: Conceptual, strategic, and statistical considerations. Journal of Personality and Social Psychology, 51(6), 1173-1182.

Baumeister, R. F., \& Leary, M. R. (1995). The need to belong: Desire for interpersonal attachments as a fundamental human motivation. Psychological Bulletin, 117(3), 497-529.

Bing, M. N., Davison, H. K., Minor, I., Novicevic, M. M., \& Frink, D. D. (2011). The prediction of task and contextual performance by political skill: A meta-analysis and moderator test. Journal of Vocational Behavior, 79(2), 563-577.

Bowling, N. A., Wang, Q., Tang, H. Y., \& Kennedy, K. D. (2010). A comparison of general and work-specific measures of core self-evaluations. Journal of Vocational Behavior, 76(3), 559-566.

Breland, J. W., Treadway, D. C., Duke, A. B., \& Adams, G. L. (2007). The interactive effect of leader-member exchange and political skill on subjective career success. Journal of Leadership \& Organizational Studies, 13(3), 1-14.

Brislin, R. W. (1980). Translation and content analysis of oral and written material (pp. 389-444).

Chang, D., Ferris, D. L., Johnson, R. E., Rosen, C. C., \& Tan, J. A. (2012). Core self-evaluations: A review and evaluation of the literature. Journal of Management, 38(1), 81-128.

Chiang, Y. H., Hsu, C. C., \& Hung, K. P. (2014). Core self-evaluation and workplace creativity. Journal of Business Research, 67(7), 1405-1413.

Clapp-Smith, R., Vogelgesang, G. R., \& Avey, J. B. (2009). Authentic leadership and positive psychological capital: The mediating role of trust at the group level of analysis. Journal of Leadership \& Organizational Studies, 15(3), $227-240$.

Deci, E. L., \& Ryan, R. M. (2000). The "what" and "why" of goal pursuits: Human needs and the self-determination of behavior. Psychological Inquiry, 11(4), 227-268.

Den Hartog, D. N., \& Belschak, F. D. (2012). When does transformational leadership enhance employee proactive behavior? The role of autonomy and role breadth self-efficacy. Journal of Applied Psychology, 97(1), 194-202.

Ferris, G. R., Treadway, D. C., Kolodinsky, R. W., Hochwarter, W. A., Kacmar, C. J., Douglas, C., \& Frink, D. D. (2005). Development and validation of the political skill inventory. Journal of Management Official Journal of the Southern Management Association, 31(1), 126-152.

Ferris, G. R., Treadway, D. C., Perrewé, P. L., Brouer, R. L., Douglas, C., \& Lux, S. (2007). Political skill in organizations. Journal of Management, 33(3), 290-320.

Fuller, B., Marler, L. E., Hester, K., \& Otondo, R. F. (2015). Leader reactions to follower proactive behavior: Giving credit when credit is due. Human Relations, 68(6), 879-898.

Gardner, W. L., Avolio, B. J., Luthans, F., May, D. R., \& Walumbwa, F. (2005). "Can you see the real me?" A self-based model of authentic leader and follower development. Leadership Quarterly, 16(3), 343-372.

Grant, A. M., \& Ashford, S. J. (2008). The dynamics of proactivity at work. Research in Organizational Behavior, 28(28), 3-34.

Grant, A. M., Gino, F., \& Hofmann, D. A. (2011). Reversing the extraverted leadership advantage: The role of employee proactivity. Academy of Management Journal, 54(3), 528-550.

Greguras, G. J., \& Diefendorff, J. M. (2009). Different fits satisfy different needs: Linking person-environment fit to employee commitment and performance using self-determination theory. Journal of Applied Psychology, 94(2), 465-477.

Griffin, M. A., Neal, A., \& Parker, S. K. (2007). A new model of work role performance: Positive behavior in uncertain and interdependent contexts. Academy of Management Journal, 50(2), 327-347.

Hayes, A. F. (2013). Introduction to mediation, moderation, and conditional process analysis: A regression-based approach. Journal of Educational Measurement, 51(3), 335-337.

Hoch, J. E., Bommer, W. H., Dulebohn, J. H., \& Wu, D. (2016). Do ethical, authentic, and servant leadership explain variance above and beyond transformational leadership? A meta-analysis. Journal of Management, 44(2), 501-529.

Hsiung, H. H. (2012). Authentic leadership and employee voice behavior: A multilevel psychological process. Journal of Business Ethics, 107(3), 349-361.

Jaiswal, D., \& Dhar, R. L. (2016). Impact of perceived organizational support, psychological empowerment and leader member exchange on commitment and its subsequent impact on service quality. International Journal of Productivity \& Performance Management, 65(1), 58-79.

Johnson, E. C., Kristof-Brown, A. L., Vianen, A. E. M. V., Pater, I. E. D., \& Klein, M. R. (2010). Expatriate social ties: Personality antecedents and consequences for adjustment. International Journal of Selection \& Assessment, 11(4), 277-288.

Judge, T. A., Bono, J. E., Erez, A., \& Locke, E. A. (2005). Core self-evaluations and job and life satisfaction: The role of selfconcordance and goal attainment. Journal of Applied Psychology, 90(2), 257-268.

Judge, T. A., Erez, A., Bono, J. E., \& Thoresen, C. J. (2003). The core self-evaluations scale: Development of a measure. Personnel Psychology, 56(2), 303-331.

Judge, T. A., Locke, E. A., \& Durham, C. C. (1997). The dispositional causes of job satisfaction: A core evaluations approach. Research in Organizational Behavior, 19(1), 151-188.

Judge, T. A., Locke, E. A., Durham, C. C., \& Kluger, A. N. (1998). Dispositional effects on job and life satisfaction: The role of core evaluations. Journal of Applied Psychology, 83(1), 17-34.

La Guardia, J. G., Ryan, R. M., Couchman, C. E., \& Deci, E. L. (2000). Within-person variation in security of attachment: A self-determination theory perspective on attachment, need fulfillment, and well-being. Journal of Personality \& Social Psychology, 79(3), 367-384.

Laschinger, H. K. S., Borgogni, L., Consiglio, C., \& Read, E. (2015). The effects of authentic leadership, six areas of worklife, and occupational coping self-efficacy on new graduate nurses' burnout and mental health: A cross-sectional study. International Journal of Nursing Studies, 52(6), 1080-1089. 
Leroy, H., Palanski, M. E., \& Simons, T. (2012). Authentic leadership and behavioral integrity as drivers of follower commitment and performance. Journal of Business Ethics, 107(3), 255-264.

Liu, J., Wang, H., Hui, C., \& Lee, C. (2012). Psychological ownership: How having control matters. Journal of Management Studies, 49(5), 869-895.

Mackinnon, D. P., Krull, J. L., \& Lockwood, C. M. (2000). Equivalence of the mediation, confounding and suppression effect. Prevention Science the Official Journal of the Society for Prevention Research, 1(4), 173-181.

Martin, S. L., Liao, H., \& Campbell, E. M. (2013). Directive versus empowering leadership: A field experiment comparing impacts on task proficiency and proactivity. Academy of Management Journal, 56(5), 1372-1395.

Mathieu, J. E., Gilson, L. L., \& Ruddy, T. M. (2006). Empowerment and team effectiveness: An empirical test of an integrated model. Journal of Applied Psychology, 91(1), 97-108.

May, D. R., Chan, A. Y. L., Hodges, T. D., \& Avolio, B. J. (2003). Developing the moral component of authentic leadership. Organizational Dynamics, 32(3), 247-260.

Meyerson, S. L., \& Kline, T. J. B. (2008). Psychological and environmental empowerment: Antecedents and consequences. Leadership \& Organization Development Journal, 29(5), 444-460.

Morrison, E. W. (2011). Employee voice behavior: Integration and directions for future research. Academy of Management Annals, 5(1), 373-412.

Morrison, E. W., \& Milliken, F. J. (2000). Organizational silence: A barrier to change and development in a pluralistic world. Academy of Management Review, 25(4), 706-725.

Morrison, E. W., \& Phelps, C. C. (1999). Taking charge at work: Extrarole efforts to initiate workplace change. Academy of Management Journal, 42(4), 403-419.

Neider, L. L., \& Schriesheim, C. A. (2011). The authentic leadership inventory (ALI): Development and empirical tests. Leadership Quarterly, 22(6), 1146-1164.

Nübold, A., Muck, P. M., \& Maier, G. W. (2013). A new substitute for leadership? Followers' state core self-evaluations. Leadership Quarterly, 24(1), 29-44

Orth, U., Trzesniewski, K. H., \& Robins, R. W. (2010). Self-esteem development from young adulthood to old age: A cohort-sequential longitudinal study. Journal of Personality \& Social Psychology, 98(4), 645-658.

Parker, S. K. (1998). Enhancing role breadth self-efficacy: The roles of job enrichment and other organizational interventions. Journal of Applied Psychology, 83(6), 835-852.

Parker, S. K., Bindl, U. K., \& Strauss, K. (2010). Making things happen: A model of proactive motivation. Journal of Management, 36(4), 827-856.

Parker, S. K., \& Collins, C. G. (2010). Taking stock: Integrating and differentiating multiple proactive behaviors. Journal of Management, 36(3), 633-662

Parker, S. K., Wall, T. D., \& Jackson, P. R. (1997). "That's not my job": Developing flexible employee work orientations. Academy of Management Journal, 40(4), 899-929.

Parker, S. K., Williams, H. M., \& Turner, N. (2006). Modeling the antecedents of proactive behavior at work. Journal of Applied Psychology, 91(3), 636-652.

Preacher, K. J., \& Hayes, A. F. (2004). SPSS and SAS procedures for estimating indirect effects in simple mediation models. Behavior Research Methods Instruments \& Computers, 36(4), 717-731.

Rego, A., Sousa, F., Marques, C., \& Cunha, M. P. E. (2012). Authentic leadership promoting employees' psychological capital and creativity. Journal of Business Research, 65(3), 429-437.

Rego, P., Lopes, M. P., \& Nascimento, J. L. (2016). Authentic leadership and organizational commitment: The mediating role of positive psychological capital. Journal of Industrial Engineering \& Management, 9(1), 129-151.

Roberts, B. W., Walton, K. E., \& Viechtbauer, W. (2006). Patterns of mean-level change in personality traits across the life course: A meta-analysis of longitudinal studies. Psychological Bulletin, 132(1), 1-25.

Rosen, C. C., Ferris, D. L., Brown, D. J., Chen, Y., \& Yan, M. (2014). Perceptions of organizational politics: A need satisfaction paradigm. Organization Science, 25(4), 1026-1055.

Ryan, R. M., \& Deci, E. L. (2008). Self-determination theory and the role of basic psychological needs in personality and the organization of behavior. In Handbook of personality: Theory and research (Vol. 3, pp. 654-678). New York: Guilford.

Shapiralishchinsky, O., \& Tsemach, S. (2014). Psychological empowerment as a mediator between teachers' perceptions of authentic leadership and their withdrawal and citizenship behaviors. Educational Administration Quarterly, 50(4), 675-712.

Shi, J., Chen, Z., \& Zhou, L. (2011). Testing differential mediation effects of sub-dimensions of political skills in linking proactive personality to employee performance. Journal of Business \& Psychology, 26(3), 359-369.

Shin, Y., \& Kim, M. J. (2015). Antecedents and mediating mechanisms of proactive behavior: Application of the theory of planned behavior. Asia Pacific Journal of Management, 32(1), 289-310.

Shrout, P. E., \& Bolger, N. (2002). Mediation in experimental and nonexperimental studies: New procedures and recommendations. Psychological Methods, 7(4), 422-444.

Spreitzer, G. M. (1995). Psychological empowerment in the workplace: Dimensions, measurement, and validation. Academy of Management Journal, 38(5), 1442-1465.

Ugwu, F. O., Onyishi, I. E., \& Rodríguezsánchez, A. M. (2014). Linking organizational trust with employee engagement: The role of psychological empowerment. Personnel Review, 43(3), 377-400.

Valsania, S. E., Moriano, J. A., \& Molero, F. (2016). Authentic leadership and intrapreneurial behavior: Cross-level analysis of the mediator effect of organizational identification and empowerment. International Entrepreneurship \& Management Journal, 12(1), 131-152.

Walumbwa, F. O., Avolio, B. J., Gardner, W. L., Wernsing, T. S., \& Peterson, S. J. (2008). Authentic leadership: Development and validation of a theory-based measure. Journal of Management, 34(1), 89-126.

Wanberg, C. R., Glomb, T. M., Song, Z., \& Sorenson, S. (2005). Job-search persistence during unemployment: A 10-wave longitudinal study. Journal of Applied Psychology, 90(3), 411-430.

Wang, S., \& Liu, Y. (2015). Impact of professional nursing practice environment and psychological empowerment on nurses' work engagement: Test of structural equation modelling. Journal of Nursing Management, 23(3), $287-296$.

Wei, F., Yuan, X., \& Di, Y. (2010). Effects of transactional leadership, psychological empowerment and empowerment climate on creative performance of subordinates: A cross-level study. Frontiers of Business Research in China, 4(1), 29-46. 
Wu, C. H., \& Parker, S. K. (2017). The role of leader support in facilitating proactive work behavior: A perspective from attachment theory. Social Science Electronic Publishing, 43(4), 1-46.

Yang, J., Liu, C., Zhang, Q., Zhao, W., \& Wang, C. (2015). Political skill, gender, and social network positioning of Chinese employees. Frontiers of Business Research in China, 9(3), 400-419.

Yang, Z., Chen, Q., Zhu, Y., \& Zeng, B. (2016). Is spiritual leadership one of the drivers of proactive behavior? Testing of a multiple mediating effects model. Management Review, 28(11), 191-202.

Zaabi, M. S. A. S. A., Ahmad, K. Z., \& Hossan, C. (2016). Authentic leadership, work engagement and organizational citizenship behaviors in petroleum company. International Journal of Productivity \& Performance Management, 65(6), 811-830.

Zhang, X. (2010). Linking empowering leadership and employee creativity: The influence of psychological empowerment, intrinsic motivation, and creative process engagement. Academy of Management Journal, 53(1), 107-128.

Zhao, X., Lynch, J. G., \& Chen, Q. (2010). Reconsidering Baron and Kenny: Myths and truths about mediation analysis. Journal of Consumer Research, 37(2), 197-206.

Zhou, J., Ma, Y., Cheng, W., \& Xia, B. (2014). Mediating role of employee emotions in the relationship between authentic leadership and employee innovation. Social Behavior \& Personality An International Journal, 42(8), 1267-1278.

Zhu, W. (2008). The effect of ethical leadership on follower moral identity: The mediating role of psychological empowerment. Leadership Review, 8(3), 62-73.

Submit your manuscript to a SpringerOpen ${ }^{\circ}$ journal and benefit from:

- Convenient online submission

- Rigorous peer review

- Open access: articles freely available online

- High visibility within the field

- Retaining the copyright to your article

Submit your next manuscript at $\gg$ springeropen.com 